\section{0th Sharjah International Conservation Forum for Arabia's Biodiversity}

The 2oth Annual Sharjah International Conservation Forum for Arabia's Biodiversity was held at the Breeding Centre for Endangered Arabian Wildlife in Sharjah, United Arab Emirates, during 4-7 February 2019. This Forum brought together over 200 participants from Bahrain, Iraq, Jordan, Kuwait, Lebanon, Oman, Saudi Arabia, United Arab Emirates, Yemen, and also Australia, France, Germany, Greece, New Zealand, Russia, South Africa, UK and the USA. The Sharjah workshops are hosted by the Environment and Protected Areas Authority of the Government of Sharjah, under the patronage of H.H. Sheikh Dr Sultan bin Mohammed al Qasimi, Member of the Supreme Council and Ruler of Sharjah.

The 2oth meeting had four themes. A species assessment theme looked at reintroductions and other conservation translocations. The protected areas theme applied the IUCN Global Standard for the Identification of Key Biodiversity Areas to endemic plants and freshwater habitats across the Arabian Peninsula. The veterinary theme looked at conservation medicine in zoo and wild animals. A technical session looked at the use of drones for mapping for conservation management in the United Arab Emirates.

Forum delegates applied the IUCN Guidelines for Reintroductions and Other Conservation Translocations to 68 regional case studies, including reintroductions of Arabian oryx, Arabian and sand gazelles, houbara bustard, spiny-tailed lizard, and mangroves. Projects were also classified along a spectrum of management intervention, and the challenges facing future conservation translocations, including the issue of illegal hunting and harvest, were discussed.

Taxonomic and regional working groups applied the IUCN Key Biodiversity Area Standard to 44 species of threatened Arabian plants and freshwater species, including fish, molluscs and Odonata (dragonflies and damselflies), and identified 55 sites meeting a Key Biodiversity Area threshold.

The theme of conservation medicine was chosen as a culmination of the work covered during previous Sharjah meetings, and because it linked with the species theme of conservation translocations. For veterinarians working with large collections of animals, especially those that are threatened, the prospect of using some or all of the animals under their care for potential future reintroductions is a fascinating yet daunting prospect. Careful consideration was given to the role the veterinarian plays in pre-release site preparation, disease surveillance and risk analysis, transportation, off-loading, and the critical post-release monitoring period.

In the technical session a step-by-step process for using drones for mapping was presented, including hardware selection, software options, and data capture and analysis protocols. Delegates participated in a field demonstration using mission-planning software to map vegetation inside and outside a protected area. Delegates also received a lecture, from David Gallacher of Zayed University, on the uses of drones in conservation, and current technological limitations and prospects for the future.

PHILIP SEDDON Department of Zoology, University of Otago, Dunedin, New Zealand.E-mail philip.seddon@otago.ac.nz

JoHn PereIRA Research \& Studies Department, Environment \& Protected Areas Authority, Sharjah, United Arab Emirates

GERHARD STEENKAMP Department of Companion Animal Clinical Studies, Faculty of Veterinary Science, University of Pretoria, Onderstepoort, South Africa

DAVID MALLON Division of Biology and Conservation Ecology, Manchester Metropolitan University, UK, and IUCN/Species Survival Commission

HELEN SENN Royal Zoological Society of Scotland, Edinburgh Zoo, Edinburgh, UK

SARAH MAY Conservation Consultant, Canberra, Australia

\section{Local democracy does not support conservation of an urban population of the European hamster Cricetus cricetus}

In April 2019 in Lublin, a city of 340,000 inhabitants in eastern Poland, a local referendum was held, ordered by the City Council, concerning a change of development for a c. 105 ha green area, Górki Czechowskie, which has diverse wildlife and provides important ecosystem services. Until the $1990 \mathrm{os}$ the area was a military training site. The referendum concerned a proposal to use one-third of the area for new residences. The plan threatens the largest urban population of the European hamster Cricetus cricetus in Lublin, where a density of 1.57 burrows per ha has been recorded (R. Lopucki \& A. Szelag, 2013, In Studies of Animal Biology Ecology and Conservation in European Cities, pp. 525-532, eds P. Indykiewicz et al., University of Science and Technology, Bydgoszcz, Poland).

Although categorized as Least Concern on the IUCN Red List, the European hamster is protected in many European countries, and listed in Appendix II of the Bern Convention and in Appendices II and IV of the EU Habitats Directive. The species is also threatened in Poland: its range has decreased by 90\% since 1970 (Ziomek et al., 2018, Conservation Program for the European Hamster Cricetus cricetus (Linnaeus, 1758) in Poland, Salamandra, Poznan, Poland). Sixty-eight per cent of residents voting in the referendum did not support development on the disputed area but 